\title{
Nodular Hidradenoma: A Rare Cytological Diagnosis
}

Santosh $\mathrm{T}^{\star}$, Manoj Kumar Patro, Jagdish Kumar Behera and Ashok Kumar Dash

Department of Pathology, All India Institute of Medical Sciences, Tatibandh, Raipur, India

\begin{abstract}
Nodular hidradenoma or clear cell hidradenoma are tumors of sweat gland usually seen in 20-50 years age group with female preponderance. We report a case of 45 year old female who came for FNA with a clinical suspicion of sebaceous cyst. Cytosmears showed fairly cohesive groups of uniform, oval to polygonal cells some of which showed cytoplasmic clearing. The cells were lying in a mucoid background along with good number of cyst macrophages. Cytological impression was benign adnexal tumor possibly cystic eccrine hidradenoma which was confirmed on histology as nodular hidradenoma. Cytohistological correlation readily allows differentiation of this unusual neoplasm from other benign and malignant mimics of skin tumours. The prognosis is excellent following excision.
\end{abstract}

Keywords: Nodular hidradenoma; Benign adnexal tumor; Sebaceous cyst

Abbreviations: FNAC: Fine Needle Aspiration Cytology; HA: Hidradenoma; PAS: Periodic Acid Schiff's

\section{Background}

Nodular hidradenoma (HA) otherwise called as solid cystic HA/ Eccrine acrospiroma originate from distal excretory duct of sweat gland [1]. Origin from apocrine gland of breast has been seldom noted. It's slow growing benign freely mobile solitary tumor with solid cystic consistency. Scalp, face and extremities are common locations. The usual age of presentation is 20-50 years showing female predominance. The cytological diagnosis of this tumor is difficult as it mimics other common benign and malignant skin neoplasm's. Early diagnosis by FNA helps in total excision of the tumor.

\section{Case History}

A 45 year old female presented with a solitary, well circumscribed soft cystic nodule on anterior chest wall more towards the right breast measuring $5 \times 4 \mathrm{~cm}$ since 6 months. On examination the swelling was fixed to skin, cystic on palpation and mildly tender (Figure 1). She had no history of fever or night sweats, nor any axillary lymph node swelling. A clinical impression of sebaceous cyst was given. FNAC was

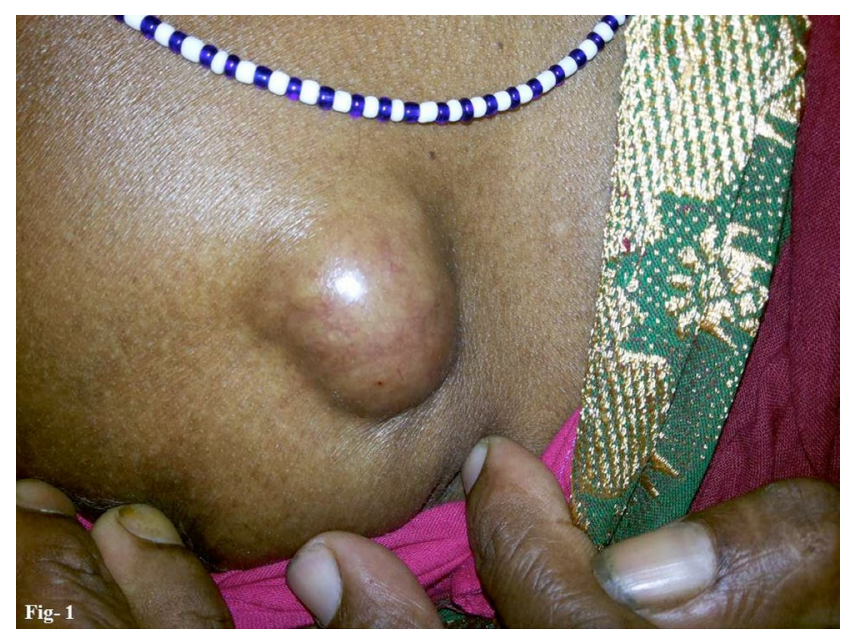

Figure 1: Swelling in anterior chest wall of size $4 \times 3 \mathrm{~cm}$ since 6 months. done which yielded a mucoid like material. Cytosmears showed fairly cohesive groups of uniform oval to polygonal cells with cytoplasmic clearing in some. The cells were lying in a mucoid background along with good number of cyst macrophages (Figure 2). There was no evidence of squamous or spindle cell component. Thus the cytologic diagnosis was given as cystic hidradenoma. Excisional biopsy showed a single skin attached soft tissue measuring $4 \times 4 \times 3 \mathrm{~cm}$, cut section was firm, solid with few cystic spaces (Figure 3 ). Histosections showed keratinized squamous epithelium beneath which the dermis showed a well circumscribed tumor separated from epidermis by a clear grenz

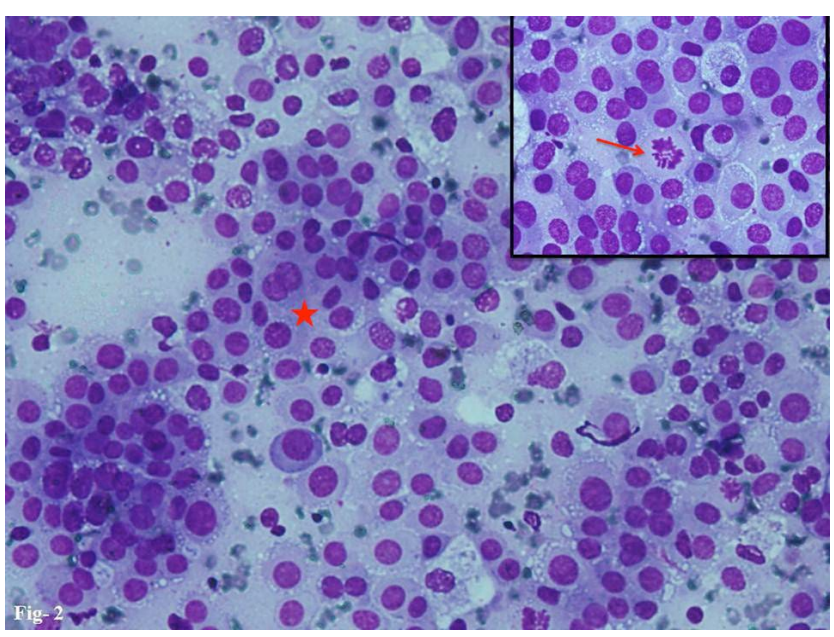

Figure 2: Cytosmears showed cohesive groups of oval to polygonal cells lying in a mucoid background (star) along with good number of cyst macrophages. Inset shows a mitotic figure (arrow) along with few cyst macrophages in background (Diff Quik 40x).

*Corresponding author: Santosh T, All India Institute of Medical Sciences, Tatibandh, G E Road, Raipur, Chhattisgarh 492 099, India, Tel: 0771-2573777; E-mail: born_vss@yahoo.co.in

Received Novenber 29, 2015; Accepted February 24, 2016; Published February 26, 2016

Citation: Santosh T, Patro MK, Behera JK, Dash AK (2016) Nodular Hidradenoma: A Rare Cytological Diagnosis. J Cancer Sci Ther 8: 048-049. doi:10.4172/19485956.1000388

Copyright: (c) 2016 Santosh T, et al. This is an open-access article distributed under the terms of the Creative Commons Attribution License, which permits unrestricted use, distribution, and reproduction in any medium, provided the original author and source are credited. 
zone. The tumor cells were uniform round cells with round bland nuclei, inconspicuous nucleoli and moderate pale eosinophilic to clear cytoplasm with distinct cell outline. The cells were arranged in lobules and ducts some of which contained PAS positive eosinophilic secretion (Figure 4). Thus the final diagnosis was given as nodular hidradenoma.

\section{Discussion}

Nodular hidradenoma was first described by Liu in 1949 as clear cell papillary carcinoma of skin [1]. Subsequently it was reported as nodular/ clear cell/solid cystic hidradenoma. It's an asymptomatic benign tumor, the size ranging from $0.5-2 \mathrm{~cm}$. It's usually covered with intact skin [2]. Occasionally may ulcerate with serous discharge especially in breast [3]. Though commonly located in head and extremities, the uncommon sites are eyelid and breast $[4,5]$. It mostly occurs in middle age. Cytologic features show a cystic component characterised by foam cells and mucoid background. The solid component shows an epithelial duct like structure. A biphasic cytologic staining pattern is observed in pap satin which varies from eosinophilic, clear cells admist

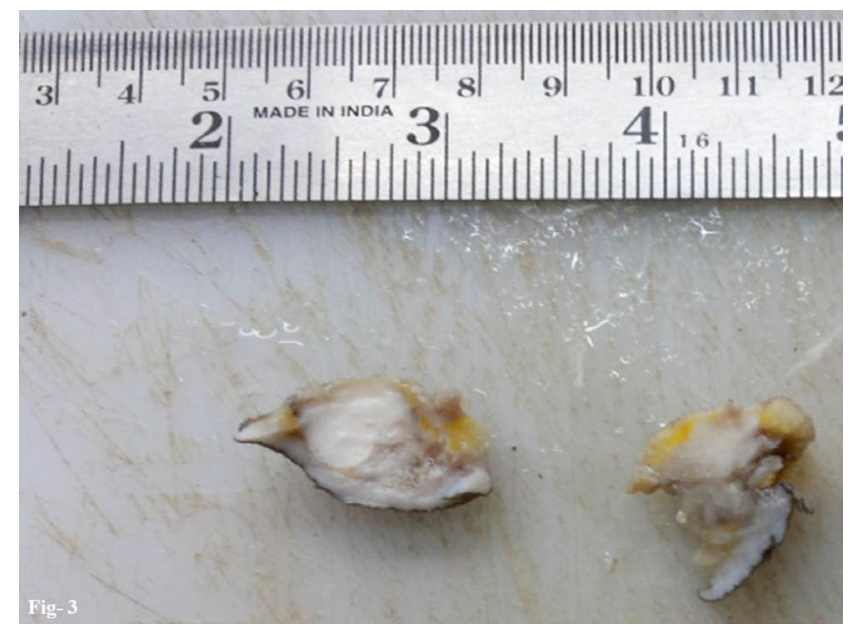

Figure 3: Skin attached soft tissue pieces $4 \times 3 \times 3 \mathrm{~cm}$, cut section is solid with a tumor present in dermis along with an grenz zone.

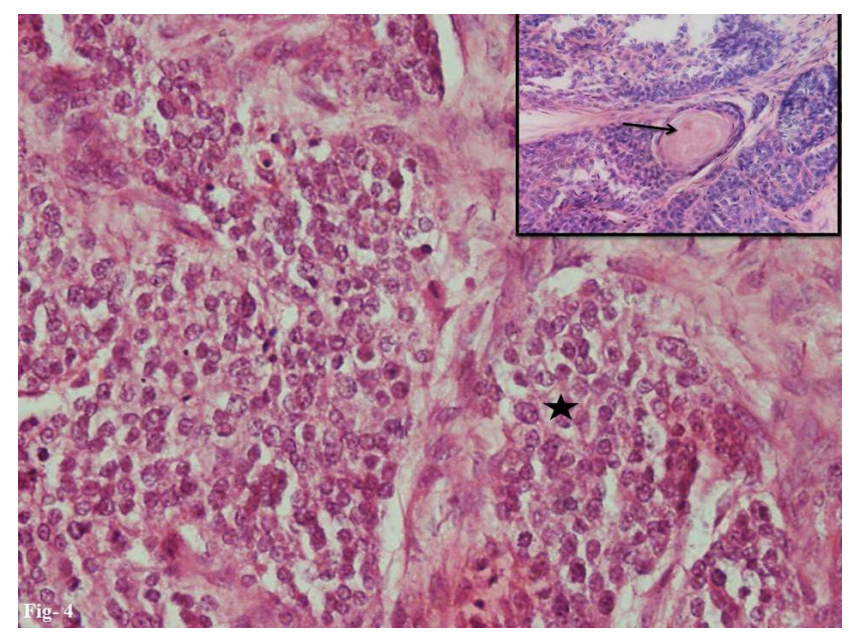

Figure 4: Histosections show tumor cells with round bland nuclei, inconspicuous nucleoli and moderate pale eosinophilic to clear cytoplasm and distinct cell outline (star). The cells were arranged in lobules and ducts some of which contained eosinophilic secretion (Inset, arrow) ( $H$ and $E, x 400$ ). pleomorphic polygonal tumor cells without tubular lumina may lead to misdiagnosis as carcinoma. This was an observation by Verma et al. in a hidradenoma located in breast [6]. Histology of nodular hidradenoma shows typical eosinophilic/clear cells along with duct like cystic spaces lined by cuboidal cells and occasional apocrine/squamous change $[1,6]$

The common cytologic differential diagnosis includes clear cell tumors of skin, glomus tumor and sebaceous cyst. Skin tumors like trichilemmoma originating from hair follicle show similar cytology but in addition show nests of basaloid cells with peripheral palisading and keratinization [2,7]. Glomus tumor show presence of blood vessels, blood elements and absence of mucoid material and foam cells. Sebaceous cyst show predominance of anucleated squames in a dirty background. Neurofibroma can be a clinical mimic which is distinguished by presence of spindle cell component [8].

Prognosis of this adnexal tumor is excellent with rare recurrence [7]. Malignant form (Hidradenocarcinoma) is extremely unusual, seen in very longstanding hidradenoma, featured by cellular atypia, prominent nucleoli and mitosis [8]. FNAC/Histology of this tumor located in breast may have intra-ductal extension and mimic ductal carcinoma [6].

\section{Conclusion}

Cytologic diagnosis of this tumor is difficult because of its rarity and variable cytologic features. FNAC diagnosis helps in accurate surgical management, thus preventing the chance of recurrence or malignancy.

\section{Author's Contributions}

TS carried out concepts and design, literature search, participated in clinical study, data acquisition, data analysis and manuscript preparation will stand as guarantor also. MP carried out concepts and design, literature search, manuscript review. JB participated in clinical study, data acquisition and manuscript review. AD carried out literature search, clinical study and data acquisition.

\section{Acknowledgement}

The authors would like to thank Prof. Debi Prasad Mishra for his constant intellectual and moral support, improvising nature.

\section{References}

1. Bagga PK, Shahi M, Nahajan NC (2009) Clear cell hidradenoma-A case report. The internet journal of pathology 8: 22.

2. Walter K, Edwad C, John TS (2005) Tumors of epidermal appendages. In Elder DE, Elentisas R, Johnson BL, Murphy GF (Eds.) Lever's histopathology of skin. (9thedn.) Lippincott Williams \& Wilkins, Philadelphia.

3. Domoto H, Terahata S, Sato K, Tamai S (1998) Nodular hidradenoma breast: Two case reports \& literature review. Pathol Int 48: 907-11.

4. Agrawala NS, Rane TM, Bhaduri AS (1999) Clear cell hidradenoma of eyelid: a case report. Indian J Pathol Microbiol 42: 361-363.

5. Dub M, Michelow $P$ (2009) Cytologic features of hidradenoma in FNAB. Acta cytol 53: 179-182.

6. Kumar N, Verma K (1996) Clear cell hidradenoma simulating breast carcinoma: a diagnostic FNA breast. Diagn cytopathol 15: 70-72.

7. Girish G, Gopasetty M, Stewart R (2006) Recurrent clear cell hidradenoma of the breast: A case report. The Internet Journal of Surgery 10: 12.

8. Lin SC, Lee MJ, Lee MS, Kee KH, Suh CH (1998) Giant hidraadeno carcinoma: a report of malignant transformation from nodular hidradenoma. Pathol Int 48 : 818-823. 